\title{
Hur underhålls en hybridstat? Indikationer från Albanien och Makedonien
}

\author{
Jessica Giandomenico*
}

Institutet för Rysslands- och Eurasienstudier, Uppsala universitet

\begin{abstract}
How is a Hybrid State Maintained? Examples from Albania and Macedonia How is a hybrid state maintained? Today, several countries undergoing democratic reforms are also backsliding towards greater authoritarianism. This article draws on election data from Macedonia and Albania to show how a country can display elements of democratic improvement and democratic deterioration within the same policy field. The Albanian case shows how the political parties, with an anchoring in legislation, work to make the electoral administration politically dependent. This enables the political parties to exert control over central aspects of the distribution of power. By contrast, the case of Macedonia shows how undemocratic behaviors can become institutionalized and gradually accepted, even as other features of the electoral process undergo improvement. Common to both countries are patterns of patronage that serve to maintain a unique organization of power: the democratic façade is improved, but the undemocratic behavior remains.
\end{abstract}

Keywords: hybrid states, elections, Balkans, Albania, Macedonia

Demokratisering efter en auktoritär regim har visat sig svårare än många hade hoppats. Även om de auktoritära dragen ersätts med en demokratisk fasad, vittnar begreppet "hybridstat", varken demokrati eller diktatur, om att steget från fasad till fungerande innehåll inte alltid är självklart. The Economist Intelligence Unit Democracy Index, till exempel, listar 57 länder (34\%) som »bristfälliga demokratier", och 40 (24\%) som hybridstater utav 167 listade stater totalt 2016. De pekar även ut de före detta kommunistiska staterna i Östeuropa som de som uppvisar den mest dramatiska regressionen rörande demokrati sedan indexet infördes 2006 (The Economist 2016). Det har visat sig att trots den uttalade viljan att införa demokrati och rättsstat, trots det starka stödet från EU och andra internationella organisationer, så fortsätter auktoritära tendenser baserade på neopatrimoniala, klientelistiska strukturer vara tydliga över det post-kommunistiska Europa. En del stater har

^Kontaktinformasjon: Jessica Giandomenico. Email: jessica.giandomenico@ires.uu.se 
reformerats till system snarlika den liberala demokratiska idealtypen, men ännu fler har institutionaliserat en blandning mellan "gammalt» och "nytt», där institutionella lager lagts på varandra (Thelen 2003) och skapat olika typer av hybridstater (Freedom House 2016).

EU och andra internationella organisationer försöker få till stånd reformer som städar bort de auktoritära och klientelistiska dragen, att införa politisk stabilitet och "politisk ordning», för att använda Fukuyamas terminologi (2015), men med blandad framgång. Vissa aspekter av en process eller policyområde kan förbättras, medan andra förblir oberörda eller till och med försämras. Hybridstaten fortsätter att formas, med nominellt demokratiska institutioner fyllda med odemokratiskt innehåll. Detta är en process som sysselsatt forskare under lång tid, men som fortfarande behöver undersökas mer på mikronivå.

På senare tid har de regimer som uppvisar starka auktoritära drag men alltjämt håller allmänna val legat $i$ fokus, och särskilt de inom sfären för det före detta Sovjetunionen. Men samma strukturer finns även inom mer demokratiskt strukturerade länder såsom de på västra Balkan under EU:s starka inflytande. De flesta av dessa länder uppvisar en tillräckligt stabil demokratisk struktur för att anses uppfylla EU:s Köpenhamnskriterier och antingen förhandlar om eller har blivit rekommenderade att öppna medlemskapsförhandlingar. Men trots detta har det visat sig oerhört svårt att följa upp med demokratiskt innehåll. Pressfriheten är urholkad, den offentliga sektorn är starkt politiserad, korruptionen är hög (Kommisionen 2014) och vi står på många sätt inför en återgång till mer auktoritära drag (BiELAG 2017). Men givet den starka demokratiska fasaden kan hybridstatens drag vara svåra att urskilja, och därmed så mycket mer nödvändiga att kartlägga och se hur de bibehålls.

Denna artikel syftar till att visa i detalj hur kampen om det klientelistiska, neopatrimoniala omsätts i praktiken under starkt utländskt inflytande, och hur svårt det är att utrota. Frågan är: hur underhålls en hybridstat? Den frågan är extra relevant när det rör sig om stater under hård extern press på att reformera sig mot starkare, mer liberal demokrati. Här är en demokratisk framtoning essentiell, men samtidigt kan reformviljan vara minimal. Målet med artikeln är att empiriskt visa hur det fungerat i två tydliga exempel, Albanien och Makedonien, där det internationella samfundet varit starkt involverat i reformarbete men där det visat sig svårt att introducera autonomi till statens institutioner, till de offentliganställda, media och det civila samhället. Studien visar på två sätt att underhålla en hybridstat under stark extern påverkan: antingen beskärs viktiga statliga institutioners autonomi i lagstiftningen, eller så institutionaliseras ett informellt, odemokratiskt, beteende genom upprepning. Men samtidigt genomförs reformer och förändringar som tillåter de internationella organisationerna att göra bedömningen att den demokratiska utvecklingen är positiv, åtminstone i ögonblicket. Det är denna dubbelhet som gör att hybridstaten underhålls. 


\section{Hybridstater och den politiska arenan}

Hybridstater är väl diskuterade i litteraturen, och innebär typiskt en stat med demokratiska förtecken såsom allmänna val och ett flerpartisystem, men samtidigt uppvisar den politiska arenan auktoritära drag, såsom begränsad autonomi för de statliga institutionerna eller tydliga praktiska och institutionella fördelar för de regerande vid val (Diamond 2002; Carothers 2002; Bogaarts 2009; Wigell 2008). Den essentiella skillnaden mellan auktoritära stater och de moderna demokratierna ligger i autonomin för statens institutioner (Fukuyama 2015). Patrimoniella, klientelistiska politiska system lämnar lite autonomi för statens institutioner, media och civilsamhället, eller ens för medborgarna själva, medan praktiskt taget total avsaknad av autonomi innebär en auktoritär regim. En liberal demokrati, å andra sidan, uppvisar hög grad av autonomi för samhällets olika delar.

Ofta diskuteras hybridstater antingen som demokratier med inskränkt autonomi för statens institutioner, massmedia och det bredare civilsamhället, eller som auktoritära stater med demokratiska inslag, såsom flerpartisystem och allmänna val, längs ett kontinuum (Levitsky \& Way 2010; Hadenius \& Teorell 2007). Initialt omnämndes hybridstater i termer av demokratisering som kommit av sig eller stannat upp (Collier \& Levitsky 1997), sedan gick studierna över till auktoritära regimer med flerpartisystem (Gandhi \& Lust-Okar 2009; Schedler 2015), men allt mer tyder på att hybridstater inte är "på väg» mot antingen den ena eller den andra regimtypen alternativt har fastnat: de har snarare institutionaliserat en egen politisk och institutionell logik och blivit en egen regimtyp (Hale 2010). Informella drag institutionaliseras och befästs i lag (O’Donnell 1996) vilket gör att det som verkade vara i förändring kan bli anmärkningsvärt stabilt (Eckstein 1988).

\section{Maktpyramiden}

Hybridstatens specifika institutionella drag berör främst hur makten är organiserad. Snarare än att samlas kring politiska partier i traditionell mening, samlas den politiska makten i vad Hale (2010) kallar politiska maskiner, ett begrepp taget från den ryska politiska arenan, som tar formen av en pyramid. Dessa politiska maskiner leds av en patron som fördelar resurser och utdelar sanktioner genom det parti han är ledare för. Under honom finns subpatroner, vilka i relation till huvudpatronen blir klienter, som kontrollerar olika delar av maktpyramiden: betrodda personer blir ministrar som kontrollerar olika politikområden med sina specifika klienter, en del är inflytelserika affärsmän, återigen med sina specifika klienter, och så vidare. Partimedlemmarna är en viktig del av dessa maktpyramiders klienter. Formellt sett ser vi enskilda politiska partier, statliga institutioner och företag, men informellt är de sammanknutna i nätverk i pyramidform med lojalitet gentemot en patron som styr. En del länder uppvisar enpyramidsystem, likt Ryssland (Hale 2015), medan andra har konkurrerande maktpyramider. Enpyramidsystem består typiskt av flera patronala nätverk under en gemensam, där de ofta konkurrerar inbördes om huvudpatronens gunst. 
Flerpyramidsystem fungerar på samma sätt, bara att flera maktpyramider konkurrerar med varandra om att dels utöka sin makt, dels om att få andra mindre nätverk att liera sig med de större. Denna politiska kamp kan se ut som demokrati, men i själva verket är det andra mekanismer involverade i olika stor utsträckning.

\section{Patronalism}

Maktpyramiden innebär att individer organiserar sina politiska och ekonomiska affärer kring ett personanpassat utbyte av belöningar och sanktioner (Hale 2015: 20). Viktigt här är att maktpyramiden är mer än en typisk klientelistisk eller (neo-)patrimoniell relation mellan väljare och parti eller politiker. Hale väljer här att introducera ett nytt begrepp, patronalism, skilt från klientelism och neopatrimonialism just för att understryka skillnaden. Han menar att konceptet klientelism är alldeles för väldefinierat för att passa in på denna typ av statsbildning. Där klientelism fokuserar på relationen mellan partier och väljare (Kitschelt \& Wilkinson 2007), är den patronala maktpyramiden mer inställd på att kontrollera nyckelpersoner inom maktpyramiden, med deras tillhörande maktpyramider. Längst ner i pyramiden ser man snarare partimedlemmar än väljare i stort, även om det givetvis finns även den typen av klientelistiska drag.

Klientelism skulle dessutom kunna ses som en prototyp av demokrati, en tidig version där de första stegen av ansvarsutkrävande mellan väljare och politiker byggs upp (Fukuyama 2015). Detta är särskilt viktigt i unga demokratier, där politikerna fortfarande lär sig hur man mobiliserar väljarna. Men detta fokus på klienterna själva och hur de kan utkräva ansvar för den förda politiken förvränger lätt bilden av hur maktpyramiden fungerar (Hale 2015: 23). Det vi ser i hybridstaterna är istället att det patronala cementeras i statens strukturer, snarare än utrotas, och att klienterna svårligen kan utkräva ansvar hos politikerna.

De hybridstater som uppkommit i demokratiseringsreformernas kölvatten karaktäriseras alltså ofta av reformer för att göra staten mer effektiv och legitim i medborgarnas och det internationella samfundets ögon, men bara till en viss gräns så att statliga organ och det civila samhället inte får en för stark autonomi. Det politiska ledarskapet försöker aktivt att skaffa sig fördelar och att göra det svårare för oppositionen att komma till makten, men utan att tappa sitt stöd hos befolkningen, eller för den del legitimitet hos de internationella organisationerna som understödjer med pengar, experthjälp och ett möjligt medlemskap i en eftertraktad organisation. Detta betyder att man når en viss mättnad rörande reformer, som genomförs till en viss gräns, men inte mer än att kontrollen över viktiga funktioner hålls tätt intill regeringen (Bolkvadze 2017). Patronalism handlar alltså om att väljare, offentliganställda, domare, media och andra knyts till maktpyramider i form av politiska partier och görs mer eller mindre beroende av dem.

Om denna maktpyramid och dess patronala system består, beskyddas eller förstärks, underhålls hybridstaten, medan den försvagas om maktpyramiden och det patronala försvagas och de enskilda individerna och institutionerna uppbundna i den åtnjuter mer autonomi. 


\section{Val som arena för maktkonfrontation}

Just som att makten i hybridstaten organiseras på ett annat sätt än i en liberal demokrati eller en diktatur, så distribueras den även annorlunda. I en demokrati är val en mekanism som väljer och auktoriserar politiska representanter genom fri konkurrens, medan val i hybridstater snarast ses som en undermålig version av den processen som ska stärkas och förbättras (Morgenbesser 2014). Men val i hybridstater har fler funktioner än så. Givetvis ger de regeringen legitimitet, dels inhemsk och även internationell. De ger även legitimitet åt själva processen. De styrande kan testa vad som är acceptabelt både hos medborgarna och det internationella samfundet innan allt för stora protester tillkännages. De kan även fungera som en mekanism inom eliten att fördela patronage emellan grupper inom en pyramid, alternativt inkorporera nya komponenter i pyramiden (Hale 2015: 68).

De här mekanismerna måste belysas och identifieras, om man inte ska fastna i samma fälla som med maktens organisering: att förändringar uppfattas som ett steg $\mathrm{i}$ en eller annan riktning, när det snarare handlar om variationer på hybridstatens speciella funktionssätt. Lindberg, till exempel, visar hur val blir språngbrädor mot nästa val i en demokratiseringsprocess. Oppositionella grupper kan till exempel genom sitt agerande "öka kostnaderna för förtryck och sänka kostnaderna för tolerans” (Lindberg 2009 321-322). På så sätt skulle alltså en demokratiseringsprocess drivas "framåt» vid varje val där ett odemokratiskt beteende uppfattas som oacceptabelt av väljarna och för politiskt kostsamt att fortsätta med för de politiska partierna. Men den logiken förutsätter att alla delar, eller i alla fall de väsentliga, genomgår en förbättring. Så är inte nödvändigtvis fallet: vissa delar av en valprocess kan förbättras, medan andra cementeras eller till och med förvärras.

De problem som pekas ut vid valen är ofta ett uttryck för den patronala maktpyramiden snarare än isolerade procedurella problem som kan utbildas bort. Men om man ser val i hybridstater som imperfekta versioner av fullödig demokrati missar man att det snarare är ett uttryck för maktens organisation och utövning. Val, dess utförande och juridiska ramverk är centrala för hybridstaten, och de ger tydliga inblickar i hur en hybridstat upprätthålls, även under en reformprocess.

\section{Design och metod}

Metodologiskt är detta en jämförande inomfallsanalys med syfte att blottlägga nya fakta om två understuderade fall för att kunna belysa hur hybridstater underhålls i praktiken. Denna data analyseras och presenteras som ett analytiskt narrativ (Levi 1997: 6), där kvalitativa data struktureras analytiskt i förhållande till teoretiska modeller. Fokus ligger på aktörerna involverade i händelseförloppet och deras aktioner för att fortsatt inskränka autonomin för väljare, statliga institutioner samt civilsamhället. Det liknar på så sätt vad George och Bennet (2005) kallar strukturerad och fokuserad jämförelse: en berättelse där data söks och presenteras på ett sätt som tillåter teoretisk analys. Inomfallsstudier är särskilt passande för fall där vi inte redan har en mängd vetenskapligt verifierade data, utan där vi behöver identifiera nyckelaktörerna, 
deras strategier och begränsningar innan vi kan ta steget till att utveckla hypoteser och förklaringsmodeller. Eftersom båda dessa två länder är understuderade rörande samhällsstrukturer och informella beteendemönster består en stor del av studien av intervjumaterial med syftet att belägga hur nyckelaktörer resonerar kring maktförhållanden, acceptabelt beteende samt vad partier och makthavare haft som mål vid reformer.

Empiriskt koncentrerar sig studien på två fall av hybridstater med primärt demokratiska förtecken: Albanien och Makedonien. De ansöker om medlemskap i EU båda två, och har därför starka incitament att förbättra och förstärka de demokratiska strukturerna av staten och samhället. Båda länderna rankas av The Economist som hybridstater under 2016. Makedonien ansågs vara en demokratisk framgång på Balkan. Landet var först med att skriva under ett Stabiliserings- och Associeringsavtal (SAA) med EU redan 2001, fick status som kandidatland 2005 och blev sedan rekommenderade att inleda medlemskapsförhandlingar av Kommissionen 2009, men det har Grekland lagt sitt veto mot sedan dess. Albanien, å andra sidan, hade stora problem att ens börja förhandla om ett SAA, vilket skrevs under 2006. Landet lämnade in sin medlemskapsansökan 2009, och fick med tvekan kandidatstatus 2013. Bland länderna på västra Balkan är dessa två länder varandras raka motsatser: de som låg först och de som låg sist i integreringsprocessen i början av 2000-talet. Freedom House demokratiindex visar att Albanien gått tillbaka på alla punkter under perioden 2008-2017 (Freedom House 2017a). Nyckelreformer rörande korruption, politiskt inflytande över rättsapparaten och vallagen kommer till stånd praktiskt taget enbart efter starka påtryckningar av det internationella samfundet. Samtidigt är Makedonien det land enligt Freedom House som gått bakåt mest på Balkan under samma period, samtidigt som många bedömare talar om en auktoritär trend (BiEPAG 2017).

Dessa två fall belyser hur hybridstaten underhålls trots stark extern påverkan och trots att länderna förbundit sig att uppfylla EU:s medlemskrav på stabila institutioner som garanterar demokrati och rättsstat (Europeiska Rådet 1993) för att nå ett av deras främsta utrikespolitiska mål. De politiska partierna har intresse av att både uppfylla EU:s villkor men samtidigt att inskränka andra aktörers autonomi av rena maktskäl.

Artikeln omfattar tidsperioden 2001-2015, men koncentrerar sig på grund av utrymmesskäl på specifika, särskilt relevanta händelser i de två länderna: dels valen 2001 och 2005 samt de efterföljande stora reformerna av valsystemet i Albanien, dels valen 2008, 2009 och 2011 i Makedonien som uppvisar stora kontraster och där EU reagerade väldigt olika inför de olika missförhållandena som uppvisades. Tyngdpunkten ligger på parlamentsval, även om det makedonska lokal- och presidentvalet 2009 står som en kontrast till parlamentsvalen 2008. De två länderna visar olika karaktärsdrag, där de albanska valen kretsar kring vallagen och dess formuleringar, och de makedonska mer kring beteendet hos de politiska partierna och deras möjligheter att agera beroende på den politiska och institutionella kontexten. På så sätt illustreras två olika sätt att underhålla en hybridstat inom samma policyområde. 
Artikeln baseras på ca 50 semistrukturerade elitintervjuer i Albanien och Makedonien gjorda under perioden 2008-2012. De intervjuade är utvalda enligt snöbollstekniken: ett initialt litet urval av strategiska personer har sedan fătt ge råd om andra lämpliga personer att intervjua. Jag riktade in mig på partiernas valexperter, valkommissionerna och de som varit inblandade i organisationen av partiernas valstrategi. Jag avslutade mitt urval när samma personer upprepades gång på gång (Tansey 2007: 770), väl medveten om att det är svårt att hitta bra intervjupersoner (Richards 1996: 201), samt att det är väldigt lätt att intervjua för många eller för få (Kvale 2007: 43). Båda dessa utmaningar är särskilt närvarande i små länder som Albanien och Makedonien, där många är inblandade men få har direkt makt och inflytande över hela processen. De flesta intervjuade önskade anonymitet, vilket respekterats. Den här typen av elitintervjuer är oftast mer datagenererande än datainsamlande (Dahl 2007: 41), på det sätt att det är forskarens uppgift att tolka innehållet och betydelsen av informationen som givits av respondenten och förmedla det till läsaren (Bedford 2009: 66; Hammersley \& Atkinson 2007: 16). Av utrymmesskäl kan bara en liten del av intervjuerna redovisas i texten, men citaten är utvalda för att tydligt illustrera vad flera intervjupersoner upprepade eller för att visa hur nyckelpersoner resonerar alternativt beskriver processen från sitt eget perspektiv.

\section{Hybridstaten i empiriskt ljus}

Det finns få vetenskapliga studier som tydligt beskriver det albanska eller det makedonska samhällets uppbyggnad och struktur. De flesta studier som berör ämnet är antingen en del av något annat eller skrivna av analytiker och tankesmedjor. Trots det kan vi mejsla fram den patronala statens drag ur den data som här finns tillgänglig.

Albanien är ett tydligt patronalt samhälle som traditionellt är organiserat $i$ maktpyramider. Landet är känt för sitt starka klansystem, där familjeband är väldigt viktiga och klanmedlemmarna är lojala mot klanledaren. Klanerna har dock i praktiken bytts ut mot politiska partier i det moderna Albanien. Dessa starka lojalitetsstrukturer har haft stora implikationer för det moderna Albaniens demokrati, där makten fortsätter att organiseras i pyramidstrukturer, där »den politiska eliten, en gång vid makten, identifierar sitt parti med staten, och beter sig som om de ägde den» (Kajsiu et al. 2003: 134). Utöver detta, så beter sig partiledare "som om de 'äger' partierna» (Bogdani \& Loughlin 2007: 143). På så sätt liknar Albanien en partistat: partiet vid makten har kontroll över statens organ.

Typiskt för maktpyramiden är att den offentliga sektorn är fylld med partilojala. EU-Kommissionen skriver att "anställningar fortsätter längs partipolitiska linjer, tvärt emot Lagen om Offentlig Anställning» (Europeiska Kommissionen 2008: 8). Personalförflyttningar är vanliga och även norm efter maktskifte eller när en minister byts ut inom en regering (Elbasani 2013). Samtidigt kan vi även konstatera att den juridiska sektorn är lika politiskt styrd: »domstolsväsendes faktiska oberoende är försvårat på grund av politiska utnämningar och andra former av politisk inblandning» 
(Bertelsmann Stiftung 2014: 11). Europarådet påpekar att det föreligger en allvarlig risk att domstolarna blir utsatta för otillbörlig påverkan genom politiska nomineringar av domare (Europarådet 2014: 2). Även medielandskapet är uppbundet i denna pyramid och kontrolleras av staten genom styrda annonsköp, en god portion självcensur på redaktionerna (Kronholm 2013; Europeiska Kommissionen 2011: 16), samt att redaktionerna är så politiskt styrda att de sänder material producerat av partierna själva (BalkanInsight 2013).

Även det makedonska samhället är patronalt strukturerat, där de politiska partierna är starkt centralstyrda, likt en pyramid, med "oligarkiska tendenser i det interna partilivet» (Siljanovska-Davkova 2005). De politiska partierna är, både centralt och lokal, vertikalt organiserade längs patronala mönster där de lokala organisationerna är styrda av de centrala (Lyon 2015). Det finns ingen eller mycket lite intern partidemokrati, och partierna tillåter inte oliktänkande fraktioner (SiljanovskaDavkova 2005), vilket reflekterar maktpyramidens logik. Avslöjandet av omfattande ljudupptagningar mellan politiker, affärsmän, religiösa ledare och andra, utförda av den makedonska säkerhetstjänsten, har visat att de patron-klientförhållanden som man tidigare trott bestått av ett flertal patroner snarast liknar en-pyramidstruktur med främst den numera före detta premiärministern Gruevski i toppen (Micevski \& Trpevska 2015). De politiska partierna vid makten styr tydligt sina medlemmar, och medlemmarna i sin tur svarar. Intervjupersonerna i studien återkom ständigt till det faktum att partierna ger direkta löften om jobb och förmåner »till exempel att de skulle få ett bättre jobb, att de skulle bli befordrade, eller att de skulle få ytterligare medel så de kan lyckas i livet», ${ }^{1}$ och att partimedlemskap är "deras enda hopp att få ett jobb, att få en position». ${ }^{2}$

Som en följd av att partierna erbjuder sina medlemmar offentlig anställning är Makedoniens offentliga sektor starkt politiserad. De folkvalda politikerna styr över tillgången till kontrakt med offentlig sektor, affärslicenser, och andra sätt att berika sig, samt tillgången på arbete. På så sätt är också Makedonien en sorts partistat, där makten är extremt centraliserad och kontrollerad (Siljanovska-Davkova 2005: 50). Den offentliga sektorn har generellt sett varit basen för att utöka de patronala strukturerna i landet eftersom staten är den största arbetsgivaren, och en officiell arbetslöshet på över $30 \% 2011$ gör att konkurrensen om jobben är hård (State Statistical Office ud). De politiska partierna tenderar till att betrakta den offentliga sektorn som "det styrande partiets egendom», vilket går i linje med maktpyramidens organisation (Cierco 2015: 490).

Den makedonska maktpyramiden sträcker sig utanför den offentliga sektorn och partipolitiken. Även här använder staten annonsköp som politiskt styrinstrument över medielandskapet (Freedom House 2013) där många observatörer uttrycker oro över hot från myndigheter mot media och journalister kritiska mot regeringen samt

${ }^{1}$ Intervju före detta DPA parlametsledamot, Gostivar, mars 2012.

${ }^{2}$ Intervju före detta VMRO-DMPNE parlamentsledamot, Skopje, februari 2012. 
regeringens kontroll över media (Europeiska Kommissionen 2014: 5; United Nations 2014). Det finns även starka indikationer på att domstolsväsendet är utsatt för allvarliga politiska påtryckningar (OSCE 2009).

Både Makedonien och Albanien uppvisar alltså tydliga maktpyramider, där de vid makten gör vad de kan för att eliminera eller inkorporera mindre och rivaliserande pyramider under deras egen kontroll. Makten uppvisar tydliga patronala drag, och båda länderna är alltså att se som hybridstater, om än med mer maktdelning och autonomi än de flesta av grannarna inom det före detta Sovjetunionen.

\section{Albanien}

Det politiska klimatet i Albanien är starkt polariserat mellan å ena sidan arvtagarna efter kommunistpartiet: det Albanska Socialistpartiet (SP) ${ }^{3}$, och det parti som föddes 1990 som en demokratisk opposition: det Demokratiska Partiet (DP). Det finns ett flertal mindre partier som antingen återuppväcktes i början på 1990-talet, såsom det Republikanska Partiet (RP) eller som knoppats av från SP respektive DP som följd av inre stridigheter. Ett typiskt exempel är den Socialistiska Rörelsen för Integrering (SMI) som leds av den före detta SP-ledaren och premiärministern Ilir Meta. Dessa partier är i praktiken satellitpartier till antingen SP eller DP, och därmed en del av maktpyramiderna.

Mycket av albansk politik kretsar kring grundläggande lagstiftning, inte minst vallagen och hur den utformar valadministrationen: vem som ska representeras och hur, vilket vittnar om att maktfördelningen ännu inte är fullt utmejslad och överenskommen. Efter varje val startar en mer eller mindre svårarbetad process att skriva om och göra tillägg till vallagen $i$ enlighet med internationella råd och rekommendationer (Giandomenico 2015). Det vi kan se i fallet Albanien är att hybridstaten har underhållits genom juridiska medel: i samband med större reformer har vallagstiftningen och även grundlagen skrivits om för att reflektera internationella experters råd, men också för att inskränka valkommissionernas autonomi och på så sätt låta partierna ta ett fastare grepp om valens organisation och utförande.

\section{En manipulerad vallagstiftning}

Det albanska parlamentet har 140 ledamöter som väljs var fjärde år. Det system som implementerades $2001 \mathrm{i}$ och med den nya grundlagen innebar att 100 ledamöter valdes genom majoritetsval i enmansvalkretsar och 40 genom ett proportionellt system. Politiskt oberoende kandidater kunde ställa upp i direktvalen, och på så sätt var valsedeln delad: man kunde rösta på en kandidat från ett parti och rösta på ett annat till de proportionellt fördelade mandaten. Algoritmen för att fördela de proportionellt valda mandaten gav fördel till de partier som fått färre direktvalda ledamöter.

${ }^{3}$ Partiernas förkortning följer den engelskspråkiga, internationellt vedertagna, förkortningen, främst för att lätt kunna återkoppla till den internationella litteraturen om respektive land. 
Detta ledde till att partierna lät en del kandidater ställa upp som oberoende kandidater inför valet som hölls 2001, fast de egentligen var partibundna. När det uppdagades blev ett antal kandidater diskvalificerade (OSCE/ODIHR 2001).

Samtidigt gav den delade valsedeln möjlighet till ett annat spel. De direkt valda mandaten avgjordes i två omgångar om ingen fick direkt majoritet på valdagen. I valdistriktet Dushk behövdes första omgången göras om på grund av oegentligheter, och det gjordes när andra omgången hölls i resten av landet två veckor senare, det vill säga när de proportionella valen redan hållits och offentliggjorts samt att man redan visste hur det gått med de flesta andra direktvalda mandaten. Här organiserade SP en beräkning om hur deras medlemmar borde rösta för att maximera antalet mandat i parlamentet, och de instruerade sedan sina medlemmar att rösta på andra partier inom deras förutbestämda koalition i direktvalen för att öka antalet mandat sammanlagt i parlamentet. Och de lyckades, för det uppdagades inte förrän valet var över. Detta kallas för Dushk-incidenten efter platsen den genomfördes på (OSCE/ODIHR 2001) och är ett typiskt uttryck för hur val i hybridstater distribuerar patronage inom maktpyramiderna.

Inför valet 2005 hade både SP och DP lärt sig sin läxa och implementerade Dushk-strategin på nationell nivå, i efterhand kallat »Mega-Dushk». Man instruerade alltså sina medlemmar till att taktikrösta på specifika kandidater och koalitionspartier, snarare än på den kandidat och det parti man faktiskt ville rösta på, för att försöka maximera antalet mandat. Och man gjorde det så väl att det tog det internationella samfundet upp till ett år att förstå vad som verkligen hade hänt. ${ }^{4}$ Men när det väl uppdagades, så blev kritiken mot partierna massiv, även från befolkningen och man insåg att något måste göras för att både den nationella och internationella legitimiteten skulle bibehållas.

Man beslöt att göra om hela valsystemet för att komma undan problemet med taktikröstning. Resultatet blev ett helt proportionellt valsystem, utan enmansdistrikt, som implementerades 2008. Men trots att de flesta av problemen som pekats ut av internationella och nationella experter adresserades i den nya vallagen, så fanns vissa delar kvar. Och det är dessa förändringar och rester av det gamla som den resterande analysen berör.

\section{Försök till förbättring}

Trots ett stort antal problem noterade av internationella observatörer, står det klart att substantiella förändringar av valsystemet har genomförts. Varje val har inneburit en ny omgång tillägg till och förändringar av vallagen, med de största förändringarna 2001 och 2008. Båda partierna förstod att Dushk och Mega-Dushk inte var framkomliga vägar, utan skadade inte bara landets anseende internationellt, men framförallt deras eget anseende bland väljarna. Nu blev de aktivt engagerade i att hitta ett nytt valsystem och en konsensus för att få igenom det med bred majoritet i parlamentet.

${ }^{4}$ Intervju senior analytiker OSSE, Tirana, mars 2009. 
En två-partikommitté sattes upp, samstyrd av SP och DP, understödd av valexperter. Resultatet blev ett proportionellt system som helt tog bort möjligheten att upprepa de tidigare förvrängningarna av valsystemet. Men detta innebar att de behövde skriva om grundlagen. När de gjorde det passade de på att ta bort den Centrala Valkommissionen (CEC) $)^{5}$ som ett konstitutionellt oberoende organ och ställde det tydligt under politisk kontroll där medlemmarna utses direkt på mandat av de politiska partierna snarare än att nomineras av dem och sedan utses av parlamentet eller presidenten. Den nya vallagstiftningen stipulerade också i exakt proportion hur många ur den underliggande valadministrationen och kommissionerna som ska utses från oppositionen och regeringskoalitionen. Skrivningarna är så exakta att eventuella förändringar av koalitionerna eller majoriteten i parlamentet under en mandatperiod innebär förändringar av valadministrationen. Detta är ett typiskt utslag av att lagstiftningen uttrycker den rådande maktbalansen snarare än en generell modell, eftersom ingen litar på att den andre vid makten kommer respektera den.

\section{Kontroll över valadministrationen}

Den patronala organisationen av samhället där allt, inklusive organisationen av val, är uppknutet i politiska lojalitetsband betyder att trots att valadministrationen i lag var politiskt obunden fram till förändringarna 2008, hade de politiska partierna kontroll över varje steg. En före detta medlem av CEC förklarade att "det är en hög politiskt komponent $\mathrm{i}$ valadministrationen (...), de två partierna sköter alla nivåer rörande val». ${ }^{6}$ Det här problemet har varit erkänt länge, både av lokala aktörer och internationella observatörer och analytiker. Det föreslagna motmedlet har varit att hålla CEC och de lägre valinstanserna juridiskt oberoende med grundlagen som stöd, samt, i teorin, ge dem lagligt skydd från politiskt inflytande. Men det har alltid ansetts som en chimär: "allt det tidigare har varit falskt, en falskt oberoende CEC, falskt oberoende medlemmar». ${ }^{7}$ En före detta ordförande för CEC bekräftade detta stora problem med de politiska partierna och att CEC »kämpade för att få kontroll över de lokala medlemmarna av valkommissionerna (...) ibland agerade de på uppdrag av deras politiska partier». ${ }^{8}$ Så trots att det brukar ses som en garanti mot valfusk att alla partier är representerade i valkommissionerna, visar det albanska exemplet att representanterna snarast är agenter med uppdrag att med alla till buds stående medel tillskansa sig röster.

En erfaren före detta medlem av valadministrationen förklarade att "specifika kommissionärer måste respektera de politiska befallningar de får, det är en del av 'kulturen'”, och de får genomgå träning inte bara hos CEC utan även hos partierna, som »inte alltid är så tekniskt orienterad utan mer en extra åtgärd mot manipulation,

${ }^{5} \mathrm{Här}$ används den engelskspråkiga förkortningen, för att lätt kunna återkoppla till den internationella litteraturen.

${ }^{6}$ Intervju före detta medlem av CEC, Tirana, mars 2009.

${ }^{7}$ Intervju DP valexpert Tirana mars 2009.

${ }^{8}$ Intervju före detta ordförande CEC, Tirana, mars 2009. 
att man blir 'immun' mot försökt att bli 'köpt'». På begäran att specificera sade han att denna praxis började spontant 2005 av SP, men blev ett etablerat inslag 2007. ${ }^{9}$ En av valexperterna sammanfattade vad de allra flesta intervjuade uttryckte: "det är enda sättet att få oberoende beteende (...) det finns fortfarande en risk att partierna uppfattar en allvarlig risk att deras medlemmar kan bli köpta av den andra sidan». ${ }^{10}$

Denna praxis kommer ur rädslan att politiska motståndare kan försöka köpa lojaliteten hos de egna medlemmarna av valkommissionerna. Detta skulle betyda att de inte längre försvarar det egna partiets röster i vallokalen, under rösträkningen samt sammanställningen av resultaten, utan motståndarens. "Alla kommissioner är fyllda med militanta partimedlemmar på grund av bristen på tillit» samt att »i slutändan så försöker alla vinna valet $\rangle^{11}$ vilket kort uttryckt betyder att en viktig del av valet utspelas i valkommissionerna själva, och att det är viktigt att ha näst intill hänsynslösa representanter, villiga att begå olika sorters oredligheter för sitt parti. Dessa kommissioner är således oerhört viktiga för utgången av valen, och näst intill lika viktiga som väljarna själva.

Istället för att försöka åtgärda detta genom att ändra sitt beteende gjorde man tvärtom: när grundlagen skrevs om 2008 för att tillåta nytt valsystem passade man på att ta bort CEC som konstitutionellt organ, och vallagen skrevs om för att ge partierna direkt kontroll över de lägre instanserna av valberedningen genom hur de nomineras, tillsätts och sanktioneras. En viktig detalj i lagstiftningen är den som reglerar hur och när medlemmarna av de kommissioner som förvaltar valdistrikten kan entledigas från sina uppgifter. Dessa kommissioner är ansvariga för bland annat distribution av valmaterial samt att räkna och sammanställa resultaten i varje valdistrikt, och här finns således en viktig arena för att manipulera valen. Lagen ger en rad skäl för entledigande som rör släktskap med kandidater, ovilja att utföra sina uppgifter, och liknande, men även när "valsubjektet som nominerade dem begär dess utbyte» (Albanska vallagen art 32, komma d) utan att behöva uppge skäl för det. Detta innebär att partierna har rättigheter att byta ut sina medlemmar av valkommissionerna när som helst, även på valdagen, och de behöver inte motivera varför. Detta är en rättighet som inte ens CEC har.

Istället för att försöka förändra ett politiserat, patronalt organiserat samhälle och offentlig sektor, så bekräftade man alltså dessa strukturer i lagen. Partierna tog full kontroll över valadministrationen genom att etablera direkt kontroll mellan parti och medlemmarna av de olika valkommissionerna, och särskilt den som handhar de mest känsliga stegen: att räkna rösterna och sammanställa resultatet.

Vi kan alltså dra slutsatsen att de politiska partierna jobbar aktivt med att stå emot förändring som innebär att valadministrationen blir mer självständig och därmed mer motståndskraftig mot politiskt inflytande, samtidigt som de gör vad de kan för att verka följa de internationella experternas råd och därmed uppvisa förbättring.

\footnotetext{
${ }^{9}$ Intervju SP medlem av flertal valkommissioner, Tirana, mars 2009.

${ }^{10}$ Intervju DP valexpert, Tirana, mars 2009.

${ }^{11}$ Intervju senior SP parlamentsledamot, Tirana, mars 2009.
} 


\section{Makedonien: från våld till hot}

Makedonien är i praktiken etniskt delat i två delar: en makedonsk, slavisk majoritet och en albansk minoritet på ca $20 \%$ av befolkningen. Den här uppdelningen är särskilt tydlig inom politiken, där de partier som vänder sig till albanerna talar albanska och inte försöker nå ut till den bredare befolkningen i någon större omfattning, medan de makedonska partierna vänder sig till den makedonsktalande befolkningen. De mindre etniska minoriteterna, såsom serber, turkar, med flera, rör sig främst inom den makedonska sfären. Konkurrensen partierna emellan inom respektive sfär är ofta hetsk med hårt språk och tuffa anklagelser dem emellan, men det är sällsynt med försök att nå ut till den andra politiska sfären och konkurrera om deras väljare. Efter den beväpnade krisen 2001 måste all lagstiftning som berör eldupphöravtalet tas med dubbel majoritet, vilket i praktiken innebär att minst ett albanskt parti måste sitta i regeringen, och därmed finns en viss överlappning, eller sammanblandning, av de annars etniskt baserade maktpyramiderna.

Sedan oberoendet 1991 har den makedonska politiken dominerats av två partier: Inre makedoniska revolutionära organisationen - demokratiska partiet för nationell enighet (VMRO-DPMNE) (högerpopulistiskt, nationalistiskt) och Makedonska Socialdemokratiska Unionen (SDSM) (vänsterorienterat, arvtagarna efter kommunistpartiet). På den albanska sidan hittar vi främst det Albanska Demokratiska Partiet (DPA) och Partiet för Demokratiskt Välstånd (PDP), fram till krisen 2001 då Demokratisk Union för Integration (DUI) växte fram ur rebellrörelsen och praktiskt taget konkurrerade ut PDP. Det makedonska parlamentet har 123 ledamöter (från 2015 120-123, beroende på utlandsrösterna) som väljs i proportionella val vart fjärde år.VMRO-DPMNE har suttit vid makten sedan valet 2006, då i koalition med DPA. Men redan 2008 sprack koalitionen med DPA, och sedan dess har VMRODMPNE samregerat med DUI. Denna koalition har varit allt annat än stabil, och det spända politiska klimatet i landet har lett till att alla parlamentsval sedan 2006 har varit nyval, ingen regering har suttit mandattiden ut. VMRO-DPMNE förlorade vid nyval 2016 efter att SDSM hade släppt tusentals ljudupptagningar mellan politiker, journalister, religiösa ledare och andra, vilket bevisade att säkerhetsorganen illegalt avlyssnat en stor del av befolkningen och att landets politiska ledning haft kontroll över en stor mängd nyckelpersoner i det makedonska samhället (Micevski \& Trpevska 2015).

Till skillnad från Albanien har inte den makedonska hybridstaten främst cementerats i lagstiftning när det gäller val, utan det handlar istället om ett allt mer utbrett odemokratiskt beteende från regeringens sida. Vallagen har genomgått förändringar och revideringar, men valsystemet är i allt väsentligt stabilt sedan den senaste större revideringen 2002. Analysen tar avstamp i valen 2008 som uppvisade skrämmande nivåer av våld. Våld som uppenbarligen sanktionerats från högsta ort och haft institutionellt stöd. Detta gjorde att legitimiteten i praktiken försvann, både i väljarnas ögon och det internationella samfundets. För att återupprätta legitimiteten satte 
regeringen in polisen och bevisade därmed att de är i full kontroll över polisen och dess aktioner.

Med våldet borta från valen kan man förledas att tro att valen blev bättre, men istället uppdagades en välorganiserad organisation att kontrollera väljarna, främst offentliganställda partimedlemmar. Det är oerhört svårt att bevisa att det skett, både vetenskapligt och juridiskt, men de internationella experterna är överens om att det förekommit i stor skala. OSSE:s valövervakare mottog flera trovärdiga tips om att offentliganställda tvingats till att bevisa att de och en rad familjemedlemmar röstar på regeringspartiet för att få behålla sociala förmåner eller till och med jobbet (OSCE/ ODIHR 2011: 10). Så snarare än att ta till juridiska medel så visar det makedonska fallet hur autonomin för väljarna kan minskas genom tvång och hot.

\section{Politiskt sanktionerat våld}

2008 års nyval var kantat av våldsamheter, främst mellan DUI och DPA i de albanskdominerade områdena i nord-väst. På flera sätt var det en förlängning av de spänningar som byggts upp redan under valet 2006, där DUI och DPA hade tagit till våldsamma metoder mot varandras lokaler och även representanter. Partilokaler attackerades nattetid, det förekom skottlossning, hot mot politiker och deras anhängare. EU-delegationen i Skopje förde loggbok på de "hårresande» händelserna ${ }^{12}$ och det stod snart klart för Statens Valkommission (SEC) att trubbel var att vänta. ${ }^{13}$ OSSE:s valobservatörer fick in rapporter om 19 attacker mot DUI-kontor, fem bortrövanden av DUI-anhängare, två attacker mot DUI-anhängares hem, en attack mot ett DPA-kontor samt sex skottlossningar (OSCE/ODIHR 2008). Dessutom blev DUI:s ledare utsatt för ett mordförsök. Valdagen var väldigt spänd med flera incidenter, och en person blev dödad i Aracinovo utanför Skopje. På grund av våldet och andra problem beslöt sig SEC för att göra om valet i 197 vallokaler utav de totalt 2976 (OSCE/ODIHR 2008: 21).

Både det internationella samfundet och Makedoniens befolkning reagerade på våldet med bestörtning och avsmak. $\mathrm{Nu}$ vaknade regeringen till och begrep att våld var en nackdel snarare än en fördel, eftersom även deras egna väljare stannade hemma av rädsla att bli beskjutna, och såg till att polisen var närvarande överallt och att ministrar, parlamentsledamöter och andra stationerades som valobservatörer inför den andra omgången. ${ }^{14}$ Denna omgång var helt lugn, och slutresultatet var en vinst för VMRO-DPMNE och DUI, som bildade regering tillsammans.

Problemet med valen 2008 hade en väldigt enkel förklaring enligt alla de intervjuade: "vad vi såg under 2008 var en kamp om att behålla makten som blev extrem», ${ }^{15}$ och »det var bara maktintressen» bakom våldet $2008 .{ }^{16}$ Och det var tydligt

\footnotetext{
${ }^{12}$ Intervju EU-delegationen, Skopje, mars 2012.

${ }^{13}$ Intervju SEC, Skopje, mars 2009.

${ }^{14}$ Intervju före detta VMRO-DPMNE minister, Skopje, februari 2012.

${ }^{15}$ Intervju DUI parlamentsledamot, Skopje, februari 2012.

${ }^{16}$ Intervju före detta DPA parlamentsledamot, Gostivar, februari 2012.
} 
att det var främst DPA som låg bakom våldet. Det kanske bästa vapnet i händerna på DPA var vice inrikesministern, en DPA-representant, och hans kontakter inom poliskåren. Han kunde låta viktiga bråkmakare inte bara arbeta ifred, utan också undlåta att arrestera dem. Enligt centralt placerade internationella aktörer så tilläts polisen att agera som "DPAs egna lilla armé». ${ }^{17}$ På så sätt fungerade polisen under hans befäl, särskilt i de albanskdominerade nordvästra delarna av landet, som en maktpyramid i den större maktpyramiden som utgörs av inrikesministeriet och i förlängningen regeringen. En högt placerad DUI-representant insisterade på att VMRO-DPMNE var involverade, eftersom »det inte är möjligt år 2008 att enbart de albanska partierna har alla dessa incidenter, alla dessa sammandrabbningar». ${ }^{18}$ Faktum är att en rad intervjuade indikerade samma sak, att DPA, DUI och VMRO-DPMNE hade en tyst överenskommelse att lämna DPA och DUI att slåss om saken ifred. "De kom överens, till och med VMRO gick med på det då, de visste vad som skulle ske». ${ }^{19}$

En före detta DPA-politiker medgav öppet att eftersom DPA visste att de skulle förlora inte bara valet utan högst troligt även deras plats i regeringen så gjorde de sitt yttersta för att "försvara rösterna", även med våld. De ville helt enkelt fylla så många valurnor som möjligt och förhindra DUI att göra detsamma. Och eftersom val är »det enda sättet att bli någon, att bli rik, att få ett jobb» så är det extra viktigt att vinna val och att kunna kontrollera "bytet», det vill säga de distribuerbara tillgångarna. ${ }^{20}$ Det här illustrerar tydligt hur maktpyramider fungerar: den vice inrikesministern hade en maktbas som utnyttjades av DPA för att se till att partiet skulle öka sin andel röster, även med illegala medel och våld. De hade uppenbarligen den högste patronens tillstånd att göra så, ända tills valens legitimitet ifrågasattes dels av det internationella samfundet, men ännu viktigare av väljarna själva.

\section{Behovet av legitimitet}

Mindre än ett år senare hölls det lokalval och presidentval. Dessa val har mycket mindre tyngd, och är på så sätt i sig själva mindre utsatta för våld och oegentligheter, men det var ändå uppenbart att händelserna 2008 hade satt sina spår. De var helt lugna från ett säkerhetsperspektiv, och både OSSE och EU var mer än nöjda med utgången, till och med lättade. EU-kommissionen rekommenderade som följd att medlemskapsförhandlingar skulle öppnas med landet. ${ }^{21}$

2009 års val visar tydligt att polisen ingår som en komponent $i$ en maktpyramid. En före detta minister hävdade att under 2009 års val så "ville inte VMRO-DPMNE

\footnotetext{
${ }^{17}$ Intervju EU-delegationen, Skopje, mars 2012.

${ }^{18}$ Intervju DUI lokalpolitiker, valexpert, Skopje, februari 2012.

${ }^{19}$ Intervju lokalt albanskt parti, RDK, Gostivar, mars 2012.

${ }^{20}$ Intervju fd DPA parlamentsledamot, Gostivar, mars 2012.

${ }^{21}$ Detta förslag röstades dock ned av Grekland. Grekland och Makedonien har ett komplicerat förhållande, där Grekland vägrar att erkänna Makedonien internationellt om inte landet byter namn. Detta är en segdragen tvist som bland annat har som konsekvens att Grekland stoppar all makedonskt inblandning i internationella organ.
} 
förstöra segern genom att något konstigt skulle hända i landet. Så därför, kan man säga, att ODIHR:s rekommendationer uppfylldes till fullo", ${ }^{22}$ vilket var hans sätt att säga att polisen är helt under partipolitisk kontroll. VMRO-DPMNE:s talesperson gav villigt förklaringen till varför valen 2009 var mycket lugnare: »vi satte ut poliser vid varje kritisk punkt» för att kontrollera situationen. ${ }^{23}$ Samma poliskår som ett år tidigare hade blundat för våldet. Vice inrikesministern hade under tiden blivit avsatt och utbytt så DPA hade inte längre någon institutionell bas att utmana DUI från, och det krävdes lugn för att bibehålla legitimiteten i valresultaten. Slutsatsen är att 2008 års val gav institutionella möjligheter till bråkmakarna, eftersom de var en integrerad del av regeringens maktpyramid. Men när den maktpyramiden omarrangerats hade inte DPA längre möjlighet att utföra osanktionerat våld. Samtidigt insåg både VMRO-DPMNE och DUI att legitimiteten för deras styre allvarligt skadats av våldet. För att återupprätta legitimiteten både i befolkningens och det internationella samfundets ögon var de tvungna att helt eliminera den komponenten av valen. Det framstod som en förbättring och som att EU:s och andras påtryckningar hade fungerat.

\section{Kontroll över väljarna}

Men samtidigt som valen verkade förbättras klagade oppositionen på att regeringspartierna, särskilt VMO-DPMNE hade utsatt väljarna, i synnerhet offentliganställda, för obehörig påverkan under valen 2009. Folk började vittna om hur de kände sig pressade att rösta för VMRO-DPMNE för att inte förlora jobbet, sociala förmåner, pensioner eller till och med tillgång till avancerad specialistvård. Den här typen av påtryckningar är oerhört svår att bevisa, men det finns en uppsjö av anekdoter, även publicerade i pressen, där en hel del är fullt trovärdigt och som tagits på allvar av internationella observatörer (OSCE/ODIHR 2009; OSCE/ODIHR 2011; BalkanInsight 2011).

Anklagelserna bestod i att VMRO-DPMNE-anhängare som fått offentlig anställning genom partiet skulle presentera listor med 15-30 namn som skulle kunna tänkas rösta för partiet. Sedan skickades de ut på arbetstid för att övertala personerna på listan att faktiskt rösta på VMRO-DPMNE också. Efteråt blev dessa personer uppringda för att kolla att de utskickade hade varit där och att de faktiskt tänkte rösta för VMRO-DPMNE. Under 2011 blev en av dessa listor på personer offentliggjord och skandalen exploderade. Den person inom VMRO-DPMNE som varit ansvarig för hela övningen berättade att dessa listor var inte för alla offentliganställda, utan bara för partiaktivister eller för »de som blivit offentligt anställda tack vare deras partitillhörighet» och dessa personer riskerade förlora "partiprivilegier» men inte sina jobb om de inte fyllde sin kvot. ${ }^{24}$ Sådan direkt kontakt mellan politik och privilegier medgavs öppet av många av de intervjuade, och bekräftar de patronala strukturerna

\footnotetext{
${ }^{22}$ Intervju fd VMRO-DPMNE minister, Skopje, februari 2012.

${ }^{23}$ Intervju VMRO-DPMNE talesperson, Skopje, februari 2012.

${ }^{24}$ Intervju VMRO-DPMNE talesperson, Skopje, februari 2012.
} 
av det makedonska samhället. Trots att detta orsakat stor skandal i Makedonien så fortsätter partierna med det. Så sent som 2014 beskrev OSSE:s valobservatörer att de bevittnat partiaktivister beordra offentliganställda att komma med listor, inklusive motsvarande personnummer, på folk de övertalat att rösta på partiet. De hade även bevittnat offentliganställda som vid valmöten undrade var de skulle skriva under för att visa att de deltagit i manifestationen (OSCE/ODIHR 2014). Detta är helt i strid med internationellt vedertagen praxis rörande demokratiska val, och är en tydlig indikation på att VMRO-DPMNE arbetade aktivt med att styra och förstärka maktpyramidens bas.

Oppositionspolitiker och analytiker reagerade och tyckte att tröskeln för acceptabla val sjönk eftersom det internationella samfundet inte kritiserade dessa oegentligheter tillräckligt, utan snarare valde att enbart se till frånvaron av våld..$^{25}$ Snarare än att fördöma, blev beteendet sanktionerat enligt dem. Dessa anklagelser fortsatte under valen 2011, och även 2014 och 2016 (OSCE/ODIHR 2014; OSCE/ ODIHR 2016). Det finns ingen anledning att tro att detta är något som började 2009, men det har med tiden blivit allt mer institutionaliserat, även efter att det blivit offentligt och djupt kritiserat. Det påverkar uppenbarligen inte legitimiteten i tillräckligt hög grad för att partierna ska sluta upp med det.

Tvärtom, allt indikerar att denna fasta kontroll har utökats till andra delar av samhället. Under 2015 släppte oppositionspartiet SDSM ljudinspelningar av samtal, gjorda av den makedonska säkerhetstjänsten utan laglig grund, som visade att regeringen försökte kontrollera affärsmän, journalister och höga ämbetsmän (Micevski \& Trpevska 2015). Upp till 20000 personer verkar ha varit föremål för dessa inspelningar, och de skapade stor oreda i den makedonska politiken samt utlöste behovet av nyval 2016, ett val som den sittande premiärministern Nicola Gruevski och hans VMRO-DPMNE förlorade till SDSM. Detta bekräftar på många sätt misstanken om att regeringen försöker styra och påverka nyckelpersoner, och går i linje med anklagelserna om att försöka påverka väljarna och det bredare samhället på ett otillbörligt sätt. Den makedonska hybridstaten har alltså underhållits genom att sakta men säkert binda upp partimedlemmar och inflytelserika personer allt starkare i maktpyramidernas patronala strukturer.

\section{Slutsatser}

Den här artikeln har visat på två sätt som en hybridstat kan underhållas: dels genom att aktivt göra tidigare nominellt autonoma institutioner satta under politisk kontroll, som det albanska exemplet visar, eller genom en långsam glidning där ett odemokratiskt beteende gång på gång befäster ett illiberalt mönster som i det makedonska fallet. Båda länderna uppvisar reformer och förändringar som ligger i

$\overline{{ }^{25} \text { Intervju SDSM }}$ parlamentsledamot, Skopje, april 2011, och intervju EU delegationen i Skopje, Bryssel, maj 2012. 
linje med vad det internationella samfundet önskar se och som de väljer att se som framgångar. Men bortom det uppenbara är bilden en helt annan.

På det hela taget brukar de stora internationella observatörerna dra slutsatsen att valen blir stadigt bättre i Albanien: organisationen blir smidigare och mer professionell, och problemen som observeras anses generellt vara isolerade händelser. Men som vi sett så har de två stora partierna i Albanien effektivt tillskansat sig full kontroll över valadministrationen, främst i praktiken, men även genom nyckelparagrafer i vallagen. De använder denna kontroll till att detaljstyra händelser i varje enskild vallokal för att kontrollera att deras röster inte komprometteras och att det andra partiet inte försöker sig på falskspel i vallokalen eller under rösträkningen. Minsta misstanke om att partifuntionärer inte är partilojala fullt ut innebär att de blir utbytta, även på valdagen. Hybridstaten underhålls genom att den demokratiska fasaden putsas upp, medan den politiska kontrollen över den viktigaste av de demokratiska institutionerna institutionaliseras i lag.

Makedonien å andra sidan visar på att beteenden i sig kan upprätthålla ett illiberalt samhälle. Ett visst beteende, till exempel våld, kan vara förödande för valens legitimitet och därmed den valda regeringens legitimitet, medan implicita hot mot en viktig del av väljarkåren inte nödvändigtvis är det. Valen 2008 visar tydligt hur den makedonska maktpyramiden under regeringen är organiserad: ett parti som innehar en ministerpost har även kontroll över just den policyfunktion som är kopplad till ministern. Vice inrikesministern hade på så vis full kontroll över polisen i de områden han ansåg viktiga, och skötte sin sektor som sin egendom. Först när det skadade regeringen i stort, grep de in för att försvara legitimiteten av sin valseger.

Men samtidigt som att regeringen under VMRO-DPMNEs ledning insåg att våld inte låg i deras direkta intressen, fortsatte de att försöka påverka väljarna genom andra typer av hot. Rapporter om otillbörlig påverkan på väljarna har förekommit under alla val, men allt tyder på att det blivit mer organiserat och strukturerat under senare år. Systemet med listor och partikontroller vittnar om ett mycket systematiskt och välorganiserat arrangemang. Det internationella samfundet hade ett bra tillfälle att fördöma detta beteende under valen 2009 , men istället ansågs valen tillräckligt fria och rättvisa för att landet skulle bli rekommenderat av EU-Kommissionen att öppna medlemskapsförhandlingar.

Båda dessa fall illustrerar tydligt hur en hybridstat kan underhållas: på ytan ser det ut som om landet tar ett steg i en demokratisk riktning, och de inblandade agerar som om det vore fallet. Men samtidigt så inskränks autonomin för olika aktörer. Även om oegentligheter vid val kan ses som enskilda incidenter (som problem med ID-kontroll av väljare och enskilda noterade fall av röstköp), så kan de samtidigt vara uttryck för hur den patronala maktpyramiden fungerar. Det är upp till observatören att förstå mekanismerna bakom.

Frågan om hur hybridstater underhålls behöver studeras mer ingående, och de olika mekanismerna som används behöver identifieras och beskrivas med större variation och detaljrikedom. Albanien och Makedonien ger varsitt exempel från ett väl 
definierat policyområde, där slutsatsen är att även i länder med starka intressen av att förstärka demokratin, så finns inte bara möjligheten utan även viljan att samtidigt bibehålla politisk kontroll över statens institutioner och medborgarna.

\section{Referenser}

Albanska vallagen (2012) antagen som lag nr 10 019, med datum 29 december 2008, ändrad genom lag nr 74/2012 dem datum 19 juli 2012, Inofficiell översättning av OSSE. Tillgänglig via www.osce.org/ albania/159501. Läsdatum 12 oktober 2017.

BalkanInsight (2011) "Voting List Scandal Casts Shadow on Macedonia Poll». Tillgänglig via www.balkaninsight.com/en/article/election-scandal-cast-shadow-on-macedonian-polls. Läsdatum 2 april 2015.

BalkanInsight (2013) "Disunity and Poverty Erode Albanian Media Freedoms», 17 juni 2013. Tillgänglig via www.balkaninsight.com/en/article/disunity-and-poverty-erode-albanian-media-freedoms. Läsdatum 10 mars 2013.

Bedford, Sofie (2009) Islamic Activism in Azerbaijan: Repression and Mobilization in a Post-Soviet Context. Doktorsavhandling. Stockholm: Statsvetenskapliga institutionen.

Bertelsmann Stiftung (2014) Albania Country Report. Gütersloh: Bertelsmann Stiftung.

BiEPAG (2017) The Crisis of Democracy in the Western Balkans. Authoritarianism and EU Stabilitocracy. Policy Paper, March 2017. Tillgänglig via www.biepag.eu/wp-content/uploads/2017/03/BIEPAG-The-Crisis-ofDemocracy-in-the-Western-Balkans.-Authoritarianism-and-EU-Stabilitocracy-web.pdf. Läsdatum 7 juli 2017.

Bogaarts, Matthijs (2009) "How to Classify Hybrid Regimes? Defective Democracy and Electoral Authoritarianism». Democratization 16 (2): 399-423.

Bogdani, Mirela \& John Loughlin (2007) Albania and the European Union: The Tumultuous fourney Towards Integration and Accession. London: IB Tauris.

Bolkvadze, Ketevan (2017) »Hitting the Saturation Point: Unpacking the Politics of Bureaucratic Reforms in Hybrid Regimes». Democratization 24 (4): 751-769.

Carothers, Thomas (2002)»The End of the Transition Paradigm». Fournal of Democracy 13 (1): 5-21.

Cierco, Teresa (2015) "Public Administration Reform in Macedonia». Communist and Post-Communist Studies 46 (4): 481-491.

Collier, David \& Steven Levitsky (1997) "Democracy with Adjectives: Conceptual Innovation in Comparative Research". World Politics 49 (3): 430-451.

Dahl, Matilda (2007) States Under Scrutiny: International Organizations, Transformation and the Construction of Progress. Doktorsavhandling. Stockholm: Företagsekonomiska institutionen.

Diamond, Larry (2002) "Thinking About Hybrid Regimes». Fournal of Democracy 13 (2): 21-35.

Eckstein, Harry (1988) "A Culturalist Theory of Political Change». The American Political Science Review 82 (3): 789-804

Elbasani, Arolda (2013) „EU Administrative Conditionality and Domestic Obstacles: Slow, Hesitant and Partial Reform in Post-Communist Albania» i Arolda Elbasani (red.) European Integration and Transformation in the Western Balkans: Europeanization or Business as Usual? Oxon: Routledge (85-100).

Europarådet (2014) »Report by Nils Muižnieks, Commissioner for Human Rights of the Council of Europe, following his visit to Albania from 23 to 27 September 2013", CommDH(2014)1, Council of Europe, Strasbourg, 16 January 2014.

Europeiska kommissionen (2008) Albania 2008 Progress Report, Brussels, 5.11.2008, SEC(2008) 2692.

Europeiska kommissionen (2011) Albania 2011 Progress report Brussels 12.10.2011 SEC(2011) 1205 final.

Europeiska kommissionen (2014) The Former Yugoslav Republic of Macedonia 2014 Progress Report, Brussels, 8.10.2014, SWD(2014) 303 final.

Europeiska Rådet (1993) Conclusions of the Presidency, European Council in Copenhagen 22-23 fune 1993, SN 180/1/93 REV 1.

Freedom House (2013) „Freedom of the Press». Tillgänglig via https://freedomhouse.org/report/freedompress/2013/macedonia\#.VP10fPnF98E. Läsdatum 9 mars 2015.

Freedom House (2016) "Nations in Transit». Tillgänglig via https://freedomhouse.org/report/nations-transit/ nations-transit-2016. Läsdatum 20 mars 2017.

Freedom House (2017a) "Nations in Transit: Albania». Tillgänglig via https://freedomhouse.org/report/nations-transit/2017/albania. Läsdatum 3 september 2017. 


\section{0 | JESSICA GIANDOMENICO}

Freedom Hourse (2017b) "Nations in Transit: Macedonia». Tillgänglig via https://freedomhouse.org/report/ nations-transit/2017/macedonia. Läsdatum 3 september.

Fukuyama, Francis (2015) Political Order and Political Decay: From the Industrial Revolution to the Globalisation of Democracy. London: Profile Books.

Gandhi, Jennifer \& Ellen Lust-Okar (2009) „Elections under Authoritarianism». Annual Review of Political Science 12 (1): 403-422.

George, Alexander \& Andrew Bennet (2004) Case Studies and Theory Development in the Social Sciences. Cambridge, Massachussets: MIT Press.

Giandomenico, Jessica (2015) Transformative Power Challenged: EU Membership Conditionality in the Western Balkans Revisited. Doktorsavhandling. Uppsala: Acta Universitatis Upsaliensis.

Hadenius, Axel \& Jan Teorell (2007) »Pathways from Authoritarianism». Fournal of Democracy 18 (1): $143-157$.

Hale, Henry (2010) "Eurasian Polities as Hybrid Regimes: The Case of Putin's Russia». Fournal of Eurasian Studies 1 (1): 33-41.

Hale, Henry (2015) Patronal Politics: Eurasian Regime Dynamics in Comparative Perspective. New York: Cambridge University Press.

Kajsiu, Blendi, Aldo Bumçi \& Albert Rakipi (2003) "Albania - A Weak Democracy A Weak State» i The inflexibility Trap: Frustrated Societies, Weak States and Democracy. State of Democracy in the Balkans. Sofia: Centre of Liberal Strategies and Institute for Market Economics (115-168).

Kitschelt, Herbert \& Steven Wilkinson (2007) "Citizen-Political Linkages: An Introduction» i Herbert Kitschelt \& Steven Wilkinson (red.) Patron Clients, and Policies: Patterns of Democratic Accountability and Political Competition. Cambridge: Cambridge University Press.

Kronholm, Axel (2013) Press Freedom in Albania, Kandidatuppsats. Göteborg: Institutionen för journalism, Media och kommunication, Göteborgs universitet.

Kvale, Steinar (2007) Doing Interviezws. London: Sage Publications.

Levi, Margaret (1997) Consent, Dissent, and Patriotism. Cambridge: Cambridge University Press.

Levitsky, Steven \& Lucan Way (2010) Competitive Authoritarianism: Hybrid Regimes after the ColdWar. New York: Cambridge University Press.

Lindberg, Staffan (2009) "A Theory of Elections as a Mode of Transition» i Staffan Lindberg (red.) Democratization by Elections: A New Mode of Transition. Baltimore och London: Johns Hopkins University Press.

Lyon, Aisling (2015) "Political Decentralization and the Strengthening of Consensual, Participatory Local Democracy in the Republic of Macedonia». Democratization 22 (1): 157-178.

Micevski, Igor \& Snezana Trpevska (2015)»What the Macedonian Phone-Tapping Scandal Tells Us about Clientelism in the Media». International fournal of Digital Television 6 (3): 319-326.

Morgenbesser, Lee (2014) »Elections in Hybrid Regimes: Conceptual Stretching Revived». Political Studies 62: 21-36.

O’Donnell, Guillermo (1996) "Illusions about Consolidation». Fournal of Democracy 7 (2): 34-51.

OSCE (2009) Legal Analysis: Independence of the Fudiciary. Skopje: OSCE Spillover Mission to Skopje.

OSCE/ODIHR (2001) Albania, Parliamentary Elections, 24 fune - 19 August 2001: Final Report, 11 oktober. Warszawa: OSCE.

OSCE/ODIHR (2008) FormerYugoslav Republic of Macedonia Early Parliamentary Elections, 1 fune 2008, OSCE/ ODIHR Election Observation Mission Final Report, 20 augusti. Warszawa: OSCE.

OSCE/ODIHR (2009) The FormerYugoslav Republic of Macedonia, Presidential and Municipal Elections, 22 March and 5 April 2009, OSCE/ODIHR Election Observation Mission Final Report, 30 juni. Warszawa: OSCE.

OSCE/ODIHR (2011) The Former Yugoslav Republic of Macedonia Early Parliamentary Elections, 5 fune 2011 OSCE/ODIHR Election Observation Mission Final Report, 6 oktober. Warszawa: OSCE.

OSCE/ODIHR (2013) Albania, Parliamentary Elections, 23 fune 2013: Final Report, 10 oktober. Warszawa: OSCE.

OSCE/ODIHR (2014) The former Yugoslav Republic of Macedonia, Presidential and Early Parliamentary Elections, 13 and 27 April, 2014: Final Report, 15 juli. Warszawa: OSCE.

OSCE/ODIHR (2017) The Former Yugoslav Republic of Macedonia Early Parliamentary Elections, 11 December 2016: Final Report, 28 februari. Warszawa: OSCE.

Richards, David (1996) "Elite Interviewing: Approaches and Pitfalls». Politics 16 (3): 199-204.

Schedler, Andreas (2015) "The Logic of Electoral Authoritarianism» i Schedler, Andreas (red.) Electoral Authoritarianism. Emerging Trends in the Social and Behavioral Sciences: An Interdisciplinary, Searchable, and Linkable Resource. Hoboken, New Jersey: John Wiley \& Sons (1-16). 
Siljanovska-Davkova, Gordana (2005) »Organizational Structures and Internal Party Democracy in the Republic of Macedonia» i Georgi Karasimeonov (red.) Organizational Structures and Internal Party Democracy in South Eastern Europe. Sofia: GorexPress (26-61).

State Statistical Office (ud) Tillgänglig via www.stat.gov.mk/OblastOpsto_en.aspx?id=14. Läsdatum 9 March 2015.

Tansey, Oisín (2007) »Process Tracing and Elite Interviewing: A Case for Non-Probability Sampling». PS: Political Science and Politics 40 (4): 765-772.

The Economist (2016) "Democracy index 2016». Tillgänglig via www.eiu.com/public/topical_report.aspx?campaignid=DemocracyIndex2016. Läsdatum 3 mars 2017.

Thelen, Kathleen (2003) "How Institutions Evolve: Insights from Comparative Historical Analysis» i James Mahoney \& Dieter Rueschemeyer (red.) Comparative Historical Analysis in the Social Sciences. New York: Cambridge University Press (208-240).

United Nations (2014) Report of the Special Rapporteur on the Promotion and Protection of the Right to Freedom of Opinion and Expression by Frank La Rue to the General Assembly, Human Rights Council, Twenty-sixth session, Agenda item 3, 1 April 2014, A/HRC/26/30/Add.2.

Wigell, Mikael (2008) "Mapping 'Hybrid Regimes': Regime Types and Concepts in Comparative Politics». Democratization 15 (2): 230-250.

\section{Intervjuer som citerats $i$ texten}

\section{Albanien}

Före detta medlem av CEC, Tirana, mars 2009

DP valexpert, Tirana, mars 2009

SP valexpert, Tirana, mars 2009

Före detta ordförande av CEC, Tirana, mars 2009

Erfaren medlem av valkommissioner, SP, Tirana, mars 2009

\section{Makedonien}

Före detta DPA parlamentsledamot, Gostivar, mars 2012

VMRO-DPMNE parlamentsledamot samt ansvarig för VMRO-DPMNE vallogistik, Skopje, februari 2012

SEC Skopje, mars, 2009

Före detta VMRO-DPMNE minister, Skopje, februari 2012

Före detta DPA parlamentsledamot, Gostivar, februari 2012

DUI lokalpolitiker, valexpert, Skopje, februari 2012

RDK lokalpolitiker, Gostivar, mars 2012

VMRO-DPMNE talersperson, Skopje, februari 2012

SDSM parlamentsledamot och före detta minister, Skopje, april 2011

\section{Övriga}

Senior analytiker, OSSE, Tirana, mars 2009

Senior analytiker EU-delegationen, Skopje, februari 2012

Chef EU-delegationen, Bryssel, maj 2012 